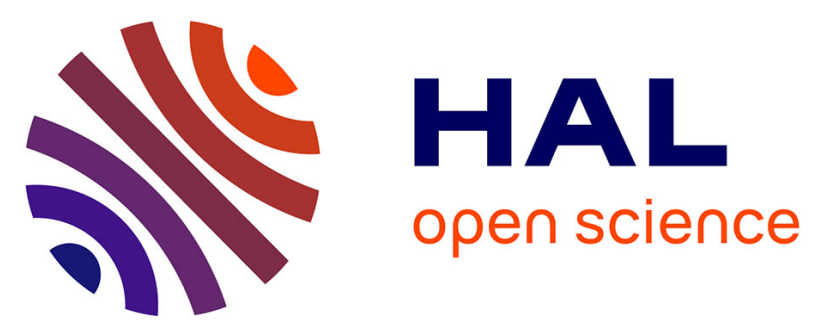

\title{
On LAGOON nose landing gear CFD/CAA computation over unstructured mesh using a ZDES approach.
}

\author{
F. de La Puente, L. Sanders, F. Vuillot
}

\section{To cite this version:}

F. de La Puente, L. Sanders, F. Vuillot. On LAGOON nose landing gear CFD/CAA computation over unstructured mesh using a ZDES approach.. AIAA AVIATION 2014 - 20th AIAA/CEAS Aeroacoustics Conference, Jun 2014, ATLANTA, United States. hal-01067878

\section{HAL Id: hal-01067878 \\ https://hal-onera.archives-ouvertes.fr/hal-01067878}

Submitted on 24 Sep 2014

HAL is a multi-disciplinary open access archive for the deposit and dissemination of scientific research documents, whether they are published or not. The documents may come from teaching and research institutions in France or abroad, or from public or private research centers.
L'archive ouverte pluridisciplinaire HAL, est destinée au dépôt et à la diffusion de documents scientifiques de niveau recherche, publiés ou non, émanant des établissements d'enseignement et de recherche français ou étrangers, des laboratoires publics ou privés. 


\title{
On LAGOON Nose Landing Gear CFD/CAA Computation over Unstructured Mesh using a ZDES approach.
}

\author{
F. De La Puente, L. Sanders, F. Vuillot
}

AIAA AVIATION 2014 - 20th AIAA/CEAS

Aeroacoustics Conference

ATLANTA, U.S.A

16-20 juin 2014

\section{ONERA}

THE FRENCH AEROSPACE LAB 

On LAGOON Nose Landing Gear CFD/CAA Computation over Unstructured Mesh using a ZDES approach.

\title{
Simulation numérique CFD/CAA du train d'atterrissage $L A G O O N$ sur maillage non-structuré en utilisant un approche ZDES.
}

\author{
par \\ F. De La Puente, L. Sanders, F. Vuillot
}

\section{Résumé traduit :}

Ce papier fait partie des efforts mis en place par I'ONERA concernant le calcul du bruit généré par les trains d'atterrissage, efforts qui portent sur plusieurs configurations comme celles comprises dans le BANC-II. L'étude présentée porte sur la géométrie LAGOON. La simulation a été réalisée avec un maillage non-structuré résolvant la couche limite jusqu'à y+ aux alentours de 1. La simulation a été réalisée en utilisant le modèle de turbulence ZDES, implémenté sur le code CEDRE développé à I'ONERA. Les données obtenues ont été utilisées afin de réaliser l'analogie de Ffowcs-Williams et Hawkings sur la surface solide du train ainsi que sur une surface poreuse qui l'englobe. Ce traitement a été fait en utilisant le code KIM, également développé à l'ONERA. Finalement, les résultats aérodynamiques et aéroacoustiques obtenus sont comparés à ceux obtenus pendant les tests réalisés au F2 et CEPRA-19. La comparaison montre un bon accord au niveau des champs moyens, de la pression pariétale (moyenne et contenu spectral) et des mesures acoustiques en champ lointain. 



\title{
On LAGOON Nose Landing Gear CFD/CAA Computation over Unstructured Mesh using a ZDES approach
}

\author{
Fernando de la Puente ${ }^{1}$, Laurent Sanders ${ }^{2}$ and Francois Vuillot ${ }^{3}$ \\ Onera - The French Aerospace Lab \\ F-92322, Châtillon, France
}

This paper is part of ONERA's effort to compute the noise generation around landing gears, effort that has been shown with studies on a variety of configurations such as the ones included inside the BANC-II (Benchmark problems for Airframe Noise Computations). In this case, the addressed geometry is the LAGOON baseline nose landing gear. On the present computation, a refined unstructured mesh is generated for resolving the boundary layer up to $\mathrm{y}^{+}$around one. The simulation of the flow was performed using a Zonal Detached Eddy Simulation (ZDES) model, implemented inside ONERA's code CEDRE. The transient data obtained were used as input for a Ffowcs-Williams and Hawkings computation over the skin of the landing gear and on a porous surface around it, which was performed using ONERA's in-house code KIM. Both the aerodynamic and aeroacoustic results are compared with the experimental ones obtained at F2 and CEPRA19 test campaigns. The comparisons obtained show a good agreement in terms of mean field, wall pressure (mean and spectral content) and aeroacoustic far-field measurements.

Nomenclature

$\begin{array}{ll}L G & =\text { Landing Gear } \\ C F D & =\text { Computational Fluid Dynamics } \\ C A A & =\text { Computational Aero Acoustics } \\ \mathrm{ZDES} & =\text { Zonal Detached Eddy Simulation } \\ M_{\infty} & =\text { Mach number } \\ \mathrm{D} & =\text { Wheel diameter } \\ \mathrm{Re} & =\text { Reynolds number } \\ \mathrm{dt} & =\text { Time step } \\ \mathrm{CFL} & =\text { Courant-Friedrichs-Lewy number } \\ \Delta & =\text { Mesh size } \\ P I V & =\text { Particle Image Velocimetry } \\ L D V & =\text { Laser Doppler Velocimetry } \\ y^{+} & =\text {Dimensionless wall distance } \\ R A N S & =\text { Reynolds-Averaged Navier-Stokes } \\ \mathrm{C}_{\mathrm{DES}} & =\text { Spalart's DES97 constant }\end{array}$

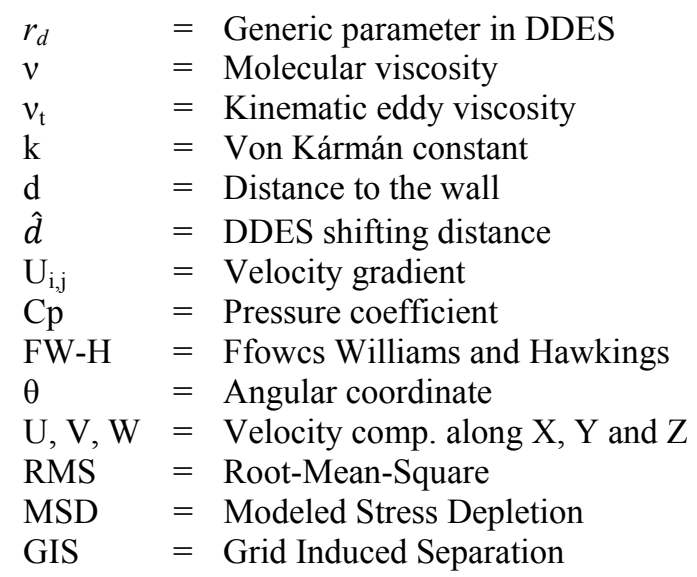

\footnotetext{
${ }^{1}$ PhD Student, CFD and Aeroacoustics Department (DSNA), fernando.de la puente@onera.fr

${ }^{2}$ Research Scientist, CFD and Aeroacoustics Department (DSNA), laurent.sanders@onera.fr

${ }^{3}$ Deputy Head, CFD and Aeroacoustics Department(DSNA), francois.vuillot@onera.fr 


\section{Introduction}

COR large airliners at approach and landing, the main noise contribution comes from the airframe itself, that T means, from the landing gear and high-lift devices. To have an idea of its magnitude, it is considered that, as much as $30 \%$ of the noise at this last flight condition comes from the deployed landing gear. In order to reduce the noise pollution around airports, large efforts are currently being made for understanding the different physical mechanisms that lie below these sources. This paper is included in the frame of this global effort, and aims for optimizing the CFD/CAA computational process to ensure a good prediction of the far field noise emitted by a simplified landing gear.

The LAGOON project, founded by AIRBUS, consists on the study of a 2:5 scaled Airbus single aisle aircraft simplified nose landing gear. The main goal of this project is to provide an extensive database for the validation of new numerical CFD/CAA tools for landing gear applications. The geometry here used is the LAGOON's baseline. This configuration has been widely tested, both aerodynamically and acoustically speaking, producing an extremely large database ${ }^{1,2}$ and leading to a wide variety of communications and publications ${ }^{3-8}$.

This baseline geometry was tested at $M_{\infty}=0.23$ and zero incidence, which corresponds to a $\mathrm{Re}=1.5410^{6}$ based on the wheel diameter $(\mathrm{D}=0.3 \mathrm{~m})$. Figure 1 shows how this geometry looks like, its main dimensions (left) and also its installation in the F2 wind tunnel for the aerodynamic test campaign (right).

The structure of the paper is as follows: in Section II we present the numerical setup used for the computation, paying special attention to the ZDES formulation. In Section III we will compare the aerodynamic results obtained numerically against the experimental ones, covering steady and transient pressure sensors, PIV and LDV measurements. In Section IV we will present the CAA computations based on FW-H analogy and compare them with the experimental results obtained at CEPRA19 test campaign. Finally, Section V will present some of the conclusions obtained.

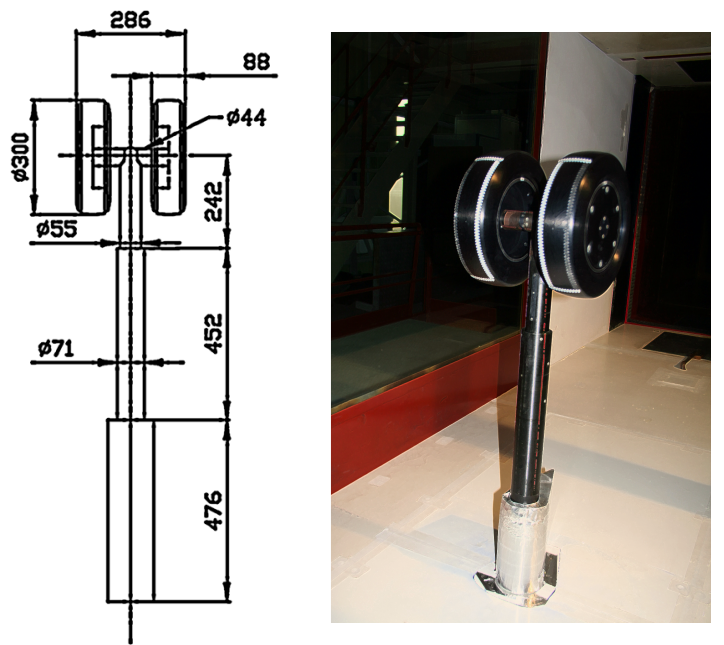

Figure 1. LAGOON baseline configuration. Main dimensions (left) and F2 wind tunnel setup (right)

\section{Computational setup}

\section{A. Hybrid RANS-LES turbulence models}

The Detached Eddy Simulation as proposed by P. Spalart in 1997 (the first version of this model is always referred as DES97) is a hybrid model that enables the use of a RANS approach (usually the Spalart-Allmaras one equation model) for the attached boundary layers, where this kind of models are very accurate and cheap, and a LES approach outside where the flow is completely detached and heavily turbulent. This approach leads to a reduction of the computational cost of a LES simulation, as the RANS approach works perfectly fine with high aspect ratio meshes used for the boundary layer discretization, while at the same time maintains a good prediction of the boundary layer development.

In order to solve some of the problems found when using the DES97 model, as the grid induced separation (GIS) or the modeled-stress depletion (MSD), a modification of this model was proposed also by P. Spalart ${ }^{10}$, this model is named Delayed Detached Eddy Simulation (DDES). The new version includes a function $\left(f_{d}\right)$ that aims for avoiding the undesired early change to LES.

This function $\left(f_{d}\right)$ is used for computing the shifting distance $\hat{d}=d-f_{d} \max \left(0, d-C_{D E S} \Delta\right)$ and shields the boundary layer. When $f_{d}=0$ the RANS mode is activated and when it equals 1 it shifts into LES. The value of $C_{D E S}$ has been calibrated to 0.65 .

$$
f_{d}=1-\tanh \left[\left(8 r_{d}\right)^{3}\right] \quad r_{d}=\frac{v_{t}+v}{\sqrt{U_{i, j} U_{i, j}} k^{2} d^{2}}
$$

The introduction of this function changes completely the behavior of the model; the shift between LES and RANS does not longer depend on the grid size but on the flow field itself. This shielding function also enables a more abrupt change between the RANS and LES mode due to its hyperbolic tangent formulation, fact that reduces 
the grey area. The lack of LES content will remain, but it will take place closer to the region where the Reynolds stresses are modeled.

On the other hand, S. Deck presented the Zonal Detached Eddy Simulation (ZDES) ${ }^{11}$. The main difference with the DDES relies on the definition of the hybrid length scale $\hat{d}$, but also on the choice, now made by the user, on where to perform RANS, LES or DES and in the case of the DES how it will be performed, protecting from MSD and GIS.

In a ZDES computation, the user has to select, for each domain, whether to perform a RANS computation or a DES one. In each DES domain, three different possibilities, called modes, are available. One of these modes, having each of them a different application and associated hybrid length scale, is to be chosen by the user. The following development is extracted from Ref. 11, where Deck presents the model:

- ZDES mode I: The separation is driven by the geometry. For example a backward facing step.

$$
\begin{aligned}
\circ \hat{d}^{I}= & \min \left(d_{w}, C_{D E S} \Delta_{I}\right) \text { where } \Delta_{I}=\Delta_{V o l} \text { or } \Delta_{\omega} \text { (depending on users selection). } \\
\text { - } & \Delta_{V o l}=\sqrt[3]{\Delta_{x} \Delta_{y} \Delta_{z}} \\
& -\Delta_{\omega}=\sqrt[2]{N_{x}^{2} \Delta_{y} \Delta_{z}+N_{y}^{2} \Delta_{z} \Delta_{x}+N_{z}^{2} \Delta_{x} \Delta_{y}} \text { where } \vec{N}=\frac{\vec{\omega}}{\|\vec{\omega}\|} \text { being } \vec{\omega} \text { the vorticity vector }
\end{aligned}
$$

- ZDES mode II: Local separation unknown a priori. For example the presence of an adverse pressure gradient over an airfoil.

$\circ \quad \hat{d}^{I I}=d_{w}-f_{d} \max \left(0, d_{w}-C_{D E S} \Delta_{I I}\right)$

$\circ \quad f_{d}$ is the original function defined by P. Spalart and previously shown. The difference between the ZDES mode II and the DDES relies on the definition of $\Delta_{I I}$ which in the case of the DDES equals to $\max \left(\Delta_{x}, \Delta_{y}, \Delta_{z}\right)$ and in the ZDES depends on the value of $f_{d}$.

$$
\text { - } \Delta_{I I}= \begin{cases}\Delta_{\max }=\max \left(\Delta_{x}, \Delta_{y}, \Delta_{z}\right) & \text { if } f_{d}<f_{d 0} \\ \Delta_{V o l} \text { or } \Delta_{\omega} & \text { if } f_{d} \geq f_{d 0}\end{cases}
$$

This definition, linked to the value of $f_{d}$ and compared to a threshold $f_{d 0}$ calibrated to 0.8 , shields the boundary layer and at the same time produces a fast transition from RANS to LES.

- ZDES mode III: Wall-Modeled LES .

$$
\circ \quad \hat{d}^{I I I}=\left\{\begin{array}{lll}
d_{w} & \text { if } & d_{w}<d_{w}^{\text {interface }} \\
\hat{d}^{I} & \text { if } & d_{w} \geq d_{w}^{\text {interface }}
\end{array}\right.
$$

- In this mode, the transition occurs at a distance $d_{w}^{\text {interface }}$ defined by the user.

In the current simulation a ZDES mode II computation was used, based on $\Delta_{V o l}$, reducing the cost of the simulation and the memory usage. It is considered that using $\Delta_{\omega}$ could improve the results, as, inside its definition, it takes into account the flow, as well as the mesh, on the contrary, $\Delta_{V o l}$ only considers the mesh topology.

\section{B. Mesh Description}

The computational domain was defined in such a way that any reflection, that could occur at the boundaries, would be dissipated without affecting the result. The main dimensions are shown in Figure 2. The boundary conditions were set to match those found during CEPRA19 test campaign.

A three dimensional unstructured hybrid mesh was built; containing 61 million elements, among those, almost 20 million prisms were devoted to resolve the boundary layer up to $\mathrm{y}^{+}$values in the order of the unity. To this end, the smallest element present at the wall had a size of $10 \mu \mathrm{m}$ along the surface normal direction.

For controlling the total number of elements in the mesh, as well as the grid resolution, a set of refinements were included all around the geometry obtaining the best compromise between these two factors. In Figure 3, the topology of the mesh is shown through the different cuts performed. In this figure, we can clearly distinguish where most of the meshing effort has been made, that is to say, the

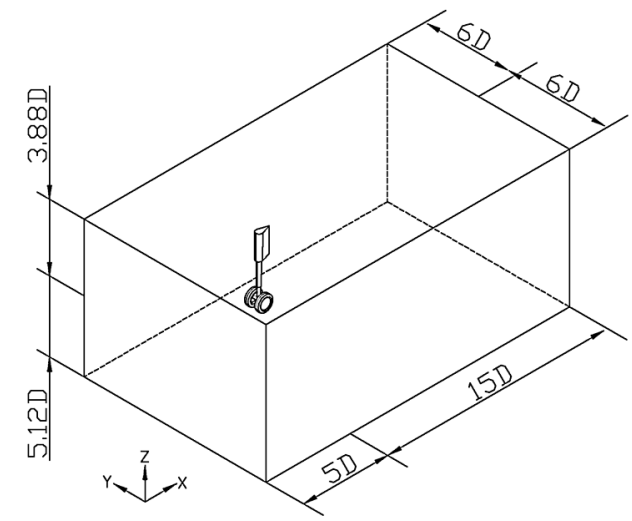

Figure 2. Computational domain surface of the landing gear and close vicinity but also the wake. 

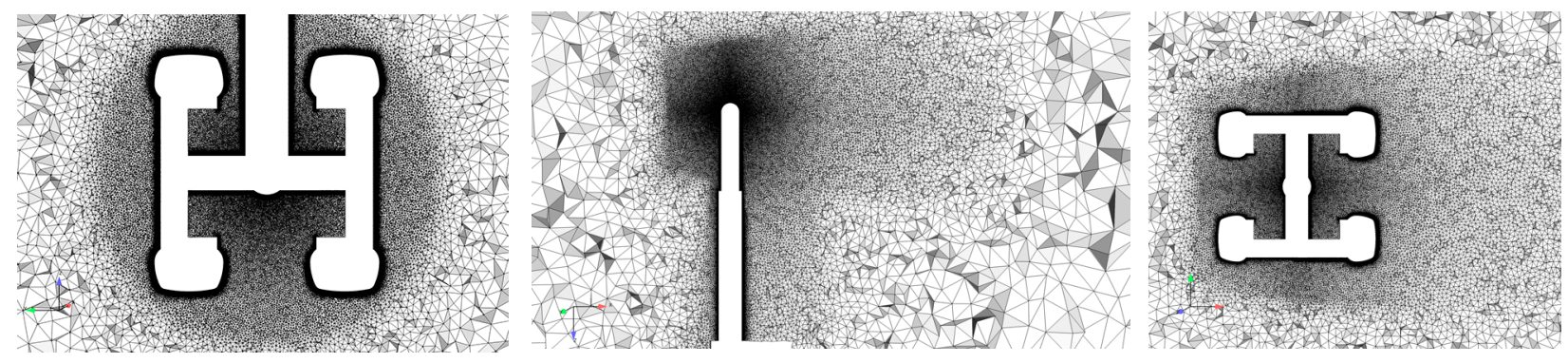

Figure 3. Mesh at $\mathrm{X}=\mathbf{0}$ (left), $\mathrm{Y}=\mathbf{0}$ (center) and $\mathrm{Z}=\mathbf{0}$ (right)

In order to ensure the flow to detach at estimated locations over the wheels and the different cylinders that form the landing gear, a sudden change in the mesh size, placed at $\theta=90^{\circ}$ with respect to the flow, was imposed to, somehow artificially introduce numerical noise. This angular position was somehow arbitrarily chosen, the flow is known to detach slightly later, but the meshing procedure was easier this way. The height of the cells downstream the change was imposed to be 5 times larger than its upstream counterpart. This methodology was successfully implemented by F. Houssen ${ }^{12}$ on a tandem cylinder configuration using the same CFD code. The effect of this change is twofold, it forces the flow as intended, but also reduces the aspect ratio of the cells behind it, improving the performance of the LES and better approaching the hypothesis of the homogeneous isotropic turbulence. In Figure 4, we can appreciate how this mesh size change (left) also induces a variation of the $y^{+}$values from upstream to downstream (right). The value of the $y^{+}$in the upstream part is in generally bounded by 1.5 , hence, when the mesh size is modified, the $y^{+}$downstream rises up to 7.5. The cavities of the wheel are not meshed with prisms, as the flow in that region is expected to be completely detached and highly turbulent.
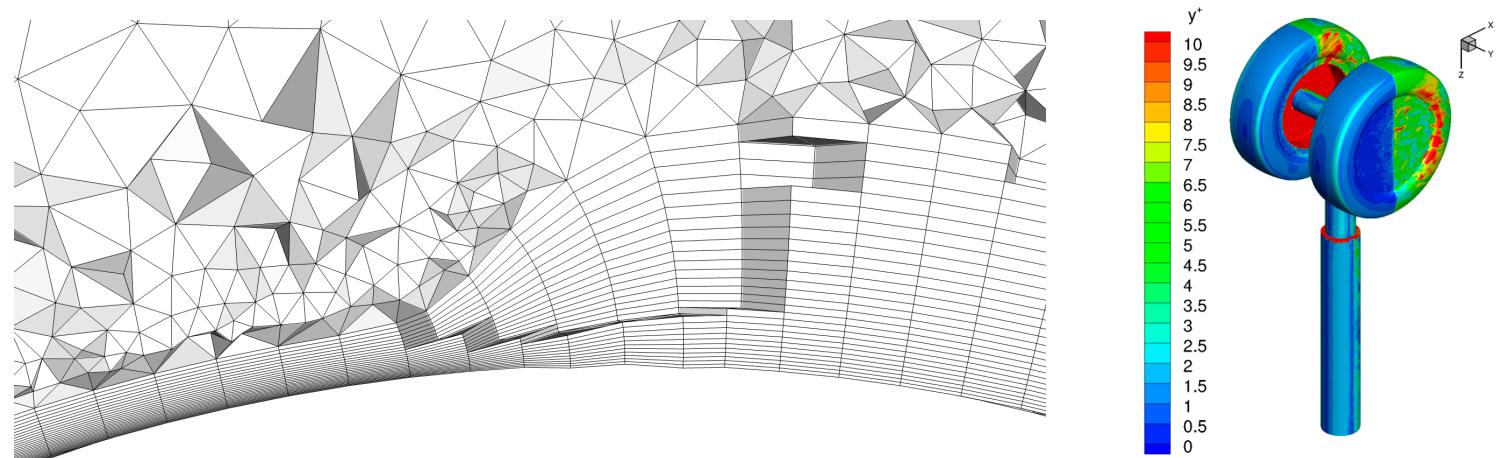

Figure 4. Mesh size sudden change at $\theta=90^{\circ}$ for right wheel (left) and $y^{+}$value at the landing gear surface (right)

\section{Numerical setup}

The computation has been initialized with a URANS k- $\omega$ SST turbulence model and a large time step, in order to produce a statistically converged mean field, achieved after 1.8 seconds of flow time. For the ZDES part, the global time step was set to $1 \mu \mathrm{s}$ in order to guarantee a CFL number lower than unity in most of fluid domain, the prisms around the wall had a slightly higher CFL due to their aspect ratio. The chosen numerical scheme is an implicit $1^{\text {st }}$ order in time and a $2^{\text {nd }}$ order in space Roe type scheme, which ensures a relatively low computational cost and a high accuracy for the computation of the aerodynamic field and the fluctuating pressures on the surface of the landing gear (key for an accurate far-field acoustic computation). The total ZDES signal available extends up to $102 \mathrm{~ms}$. 


\section{Aerodynamic results and comparison against experiments}

In this Section, we will present some of the aerodynamic results obtained through the computation and we will compare them against the ones obtained during the test campaigns at F2.

\section{A. Mean Flow}

\section{PIV}

We will start comparing the mean field obtained after $102 \mathrm{~ms}$ of computation, although only the last $42 \mathrm{~ms}$ are used for the computation of the mean aerodynamic field. The chosen planes are the ones shown in Figure 5, for these three planes, we have extracted in Figure 6 the mean velocity components along the $\mathrm{X}$ and $\mathrm{Y}$ axis, obtaining a quite accurate mean field. The results match the experimental ones, especially at heavily turbulent locations, such as the plane $Z=0$ where the wake from both wheels merge and reaccelerate. At this same location, the crosswise component presents a less accurate agreement; the velocity is underestimated and the "hook-shaped" wake observed in the experiments is not reproduced that well, even if we perfectly recognize it.

Another remarkable difference is found at $Z=238 \mathrm{~mm}$, where we can easily appreciate a longer but narrower wake on the numerical results when compared to the experimental ones. Several reasons might explain this phenomenon; it could be due to the tripping added during the experiments, which was not reproduced in the numerical setup, or to the complexity of this region, where the diameter of the leg suddenly changes from 55 to $71 \mathrm{~mm}$ generating a step (quite challenging to properly mesh with prisms). For the crosswise component, the comparison is limited due to the presence of the wheels shadow, clearly visible in the streamwise

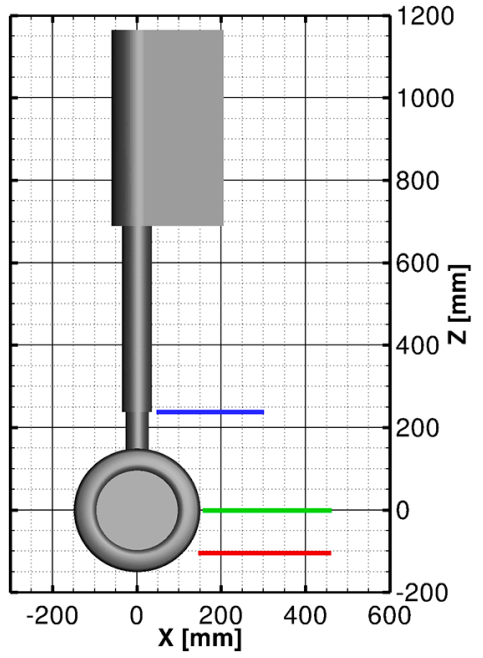

Figure 5. PIV-2D planes. $Z=-104 \mathrm{~mm}$ (red), $Z=0 \mathrm{~mm}$ (green) and $\mathrm{Z}=\mathbf{2 3 8 \mathrm { mm }}$ (blue) component that effectively reduces the size of the experimental PIV window.
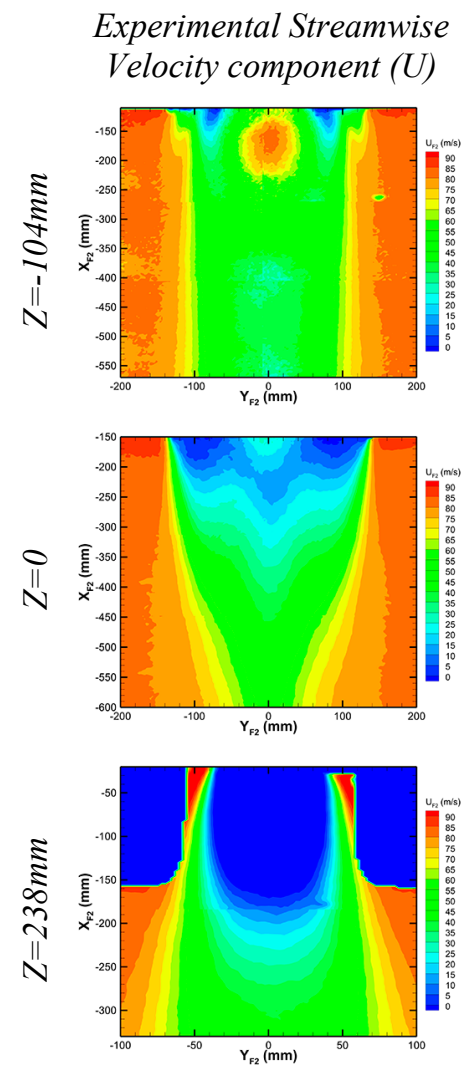

\section{Numerical Streamwise Velocity component (U)}

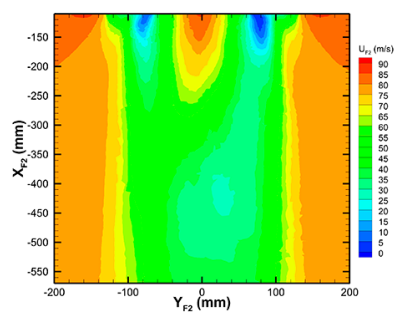

Experimental Crosswise Velocity Component ( $V$ )
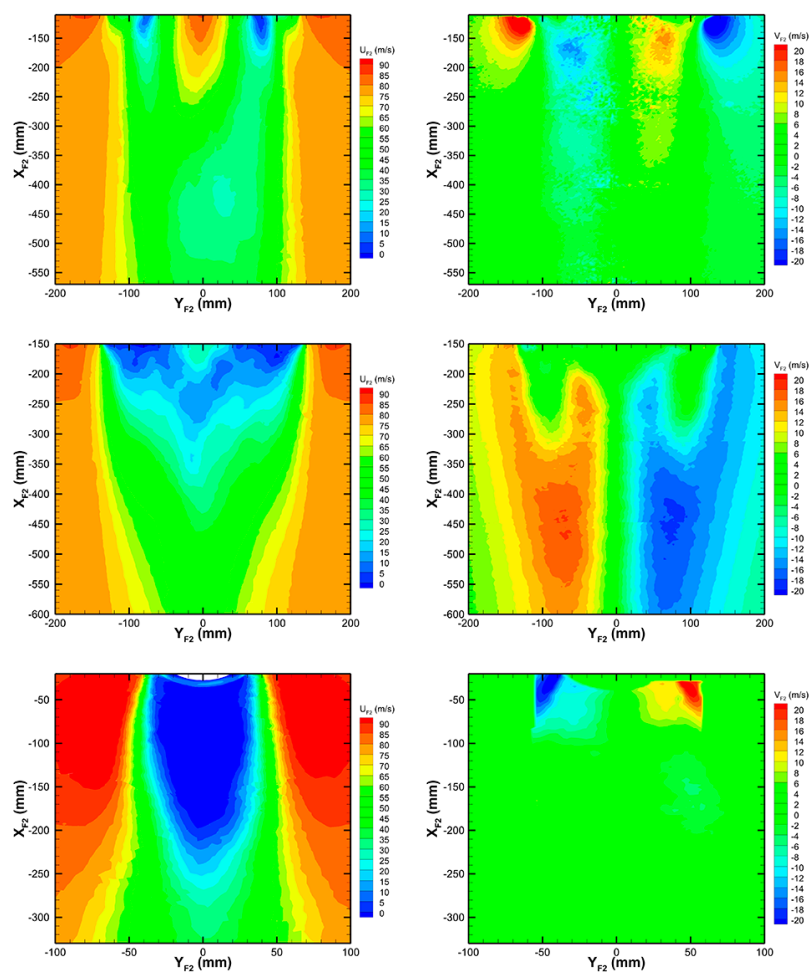

Numerical Crosswise Velocity Component (V)
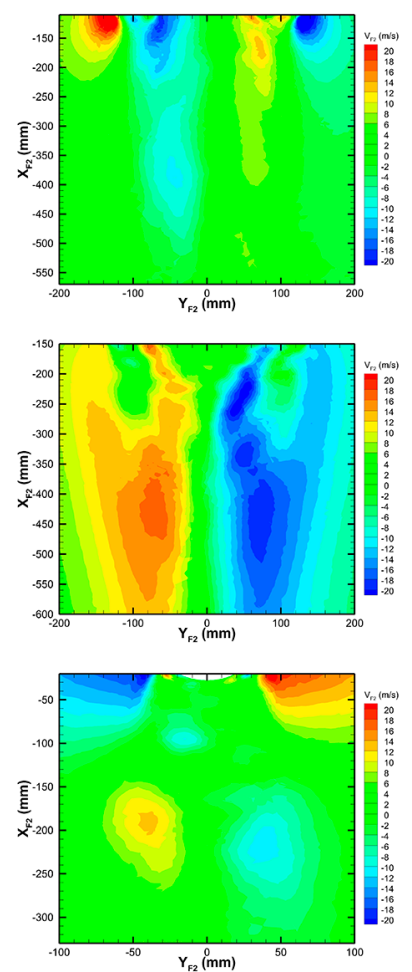

Figure 6. PIV-2D Mean Field comparison, experiments vs. CEDRE.

From top to bottom: $Z=-104, Z=0$ and $Z=238 \mathrm{~mm}$.

From left to right: $U_{\mathrm{F} 2}, \mathbf{U}_{\mathrm{CEDRE}}, \mathrm{V}_{\mathrm{F} 2}, \mathrm{~V}_{\mathrm{CEDRE}}$

5

American Institute of Aeronautics and Astronautics 


\section{Wake investigation through $L D V$}

Thanks to the highly detailed experimental database provided, an investigation of the wake topology can be envisaged; this has been performed thanks to two-dimensional LDV measurements. In Figure 7 we show the streamwise and vertical velocity component at three different locations of the wake, $X=-160,-180$ and $-220 \mathrm{~mm}$ for $\mathrm{Z}=0 \mathrm{~mm}$, both in terms of mean and RMS velocities. In the same plane we can observe the evolution of the wake in the streamwise direction $(\mathrm{Y}=-115 \mathrm{~mm})$, just behind the wheel. From the analysis of this figure and its comparison against experiments, we can state that the wake behind the wheels is well reproduced. The mean velocity is well reproduced at all stations and directions, on the other hand, the RMS velocities show an underestimation of the levels. That could be due to the tripping used during the experiments, which was not included on the present computation, but even though, the tendencies and positions of the maxima are well reproduced. Looking at the streamwise velocity survey at $Y=-115 \mathrm{~mm}$, we observe a faster growth of the experimental wake in terms of longitudinal velocity, in agreement with what is observed on the PIV. In Figure 6, the velocity deficit for $Z=0$ and $X=-400 \mathrm{~mm}$ is smaller in the experiments than in the numerical results. The difference in the vertical velocity observed in Figure 7 at $Y=-115 \mathrm{~mm}$, close to the wheel is still to be explained.

Mean Streamwise

Velocity component (U)
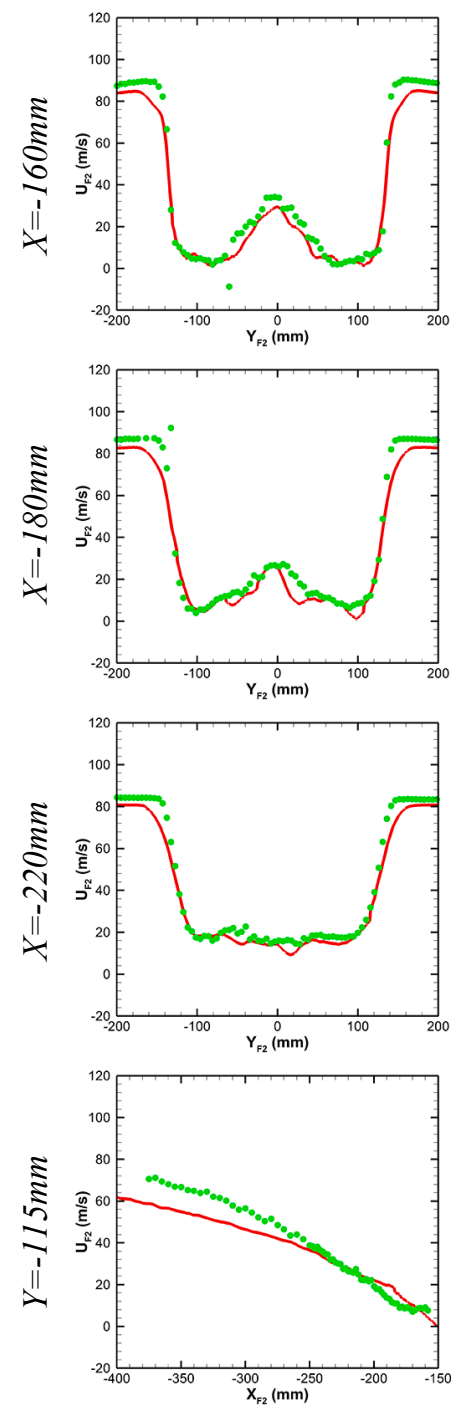

Mean Vertical Velocity component $(W)$
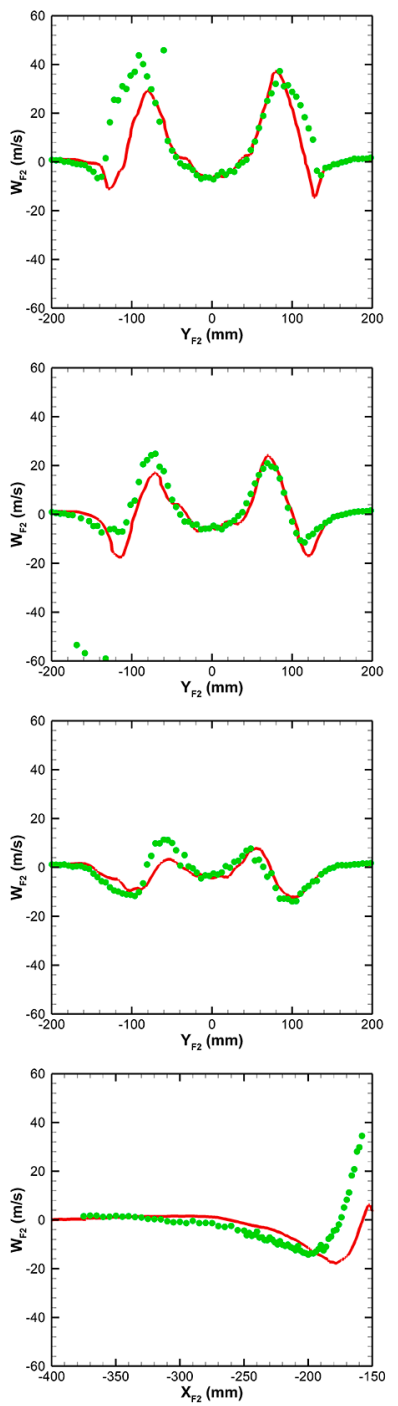

RMS Streamwise Velocity component $(U)$
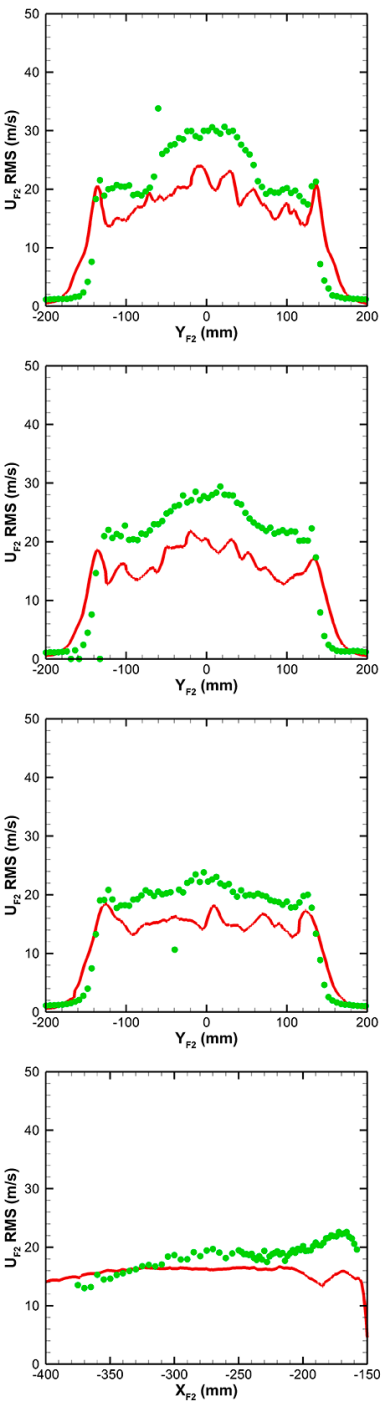

RMS Vertical Velocity component $(W)$
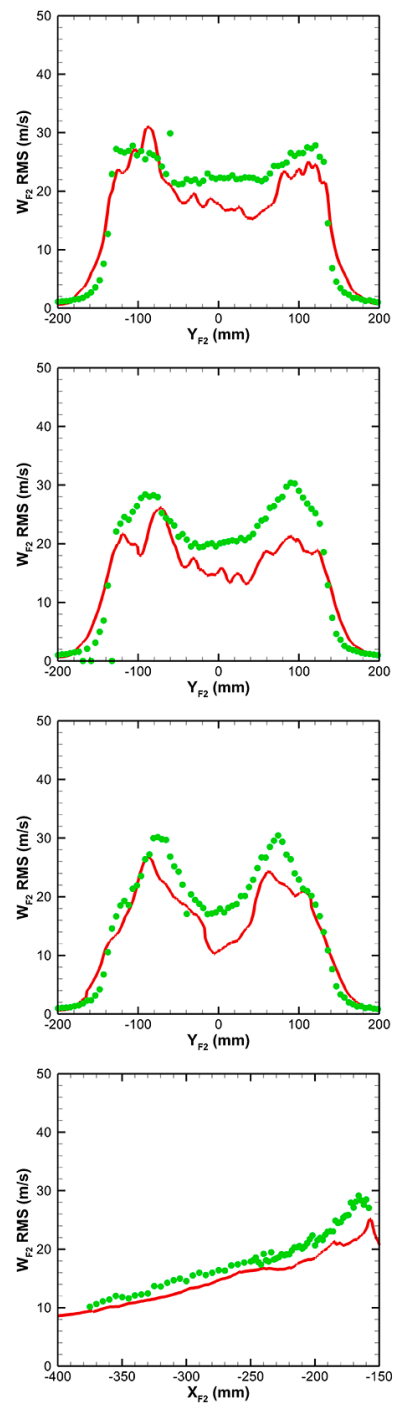

Figure 7. Wake velocity survey for $Z=0$. From top to bottom: $X=-160,-180,-220 \mathrm{~mm}$ and $Y=-115 \mathrm{~mm}$. From left to right $U, W, U_{R M S}$ and $W_{\text {RMS }}$. CEDRE in red lines, $F 2$ experiments in green dots. 


\section{Unsteady two-dimensional LDV measurements. Velocity spectra}

Once seen that the mean and RMS field are well reproduced, a study of the spectral content of the wake at different locations was carried out. Some of the results obtained are shown in Figure 8.

As for the steady LDV measurements, both the streamwise and vertical velocity components have been studied and compared to the experimental results obtained at F2. The chosen locations are found in Figure 9.

In general terms, a good agreement is found. One remarkable point is that the cut-off frequency is kept constant and about $2 \mathrm{kHz}$ for all the different locations and velocity components.

The flow between both wheels (green lines) is well reproduced in both directions, showing that the different wake interactions with the axe and the leg are well reproduced.

Concerning the flow behind the left wheel (red and dark blue lines), the agreement seems to be better for $Z=0$, especially for the vertical component. The results obtained at $Z=0$ are in good agreement with the RMS velocities shown in Figure 7, but now we can see that the main structures responsible of the underestimation seen are those with a frequency higher to $3 \mathrm{kHz}$, that are cut buy the mesh and the scheme.

On the other hand, the spectral content of flow behind the leg (light blue lines) is not that well reproduced. This could be due to the coarser mesh used at this region. We will see later that this element seems not to play a major role on the far-field noise.
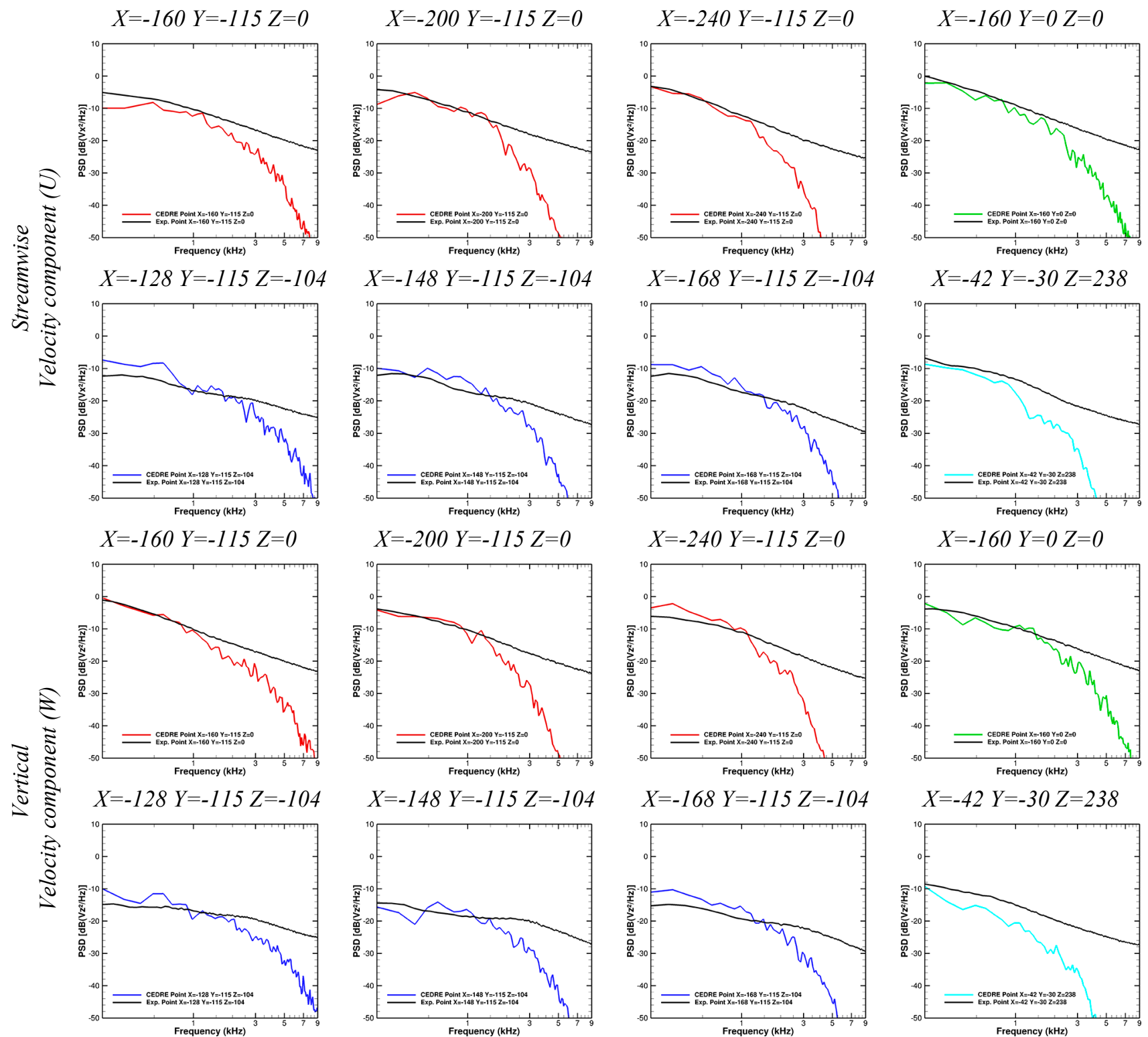

$$
X=-160 \quad Y=0 \quad Z=0
$$
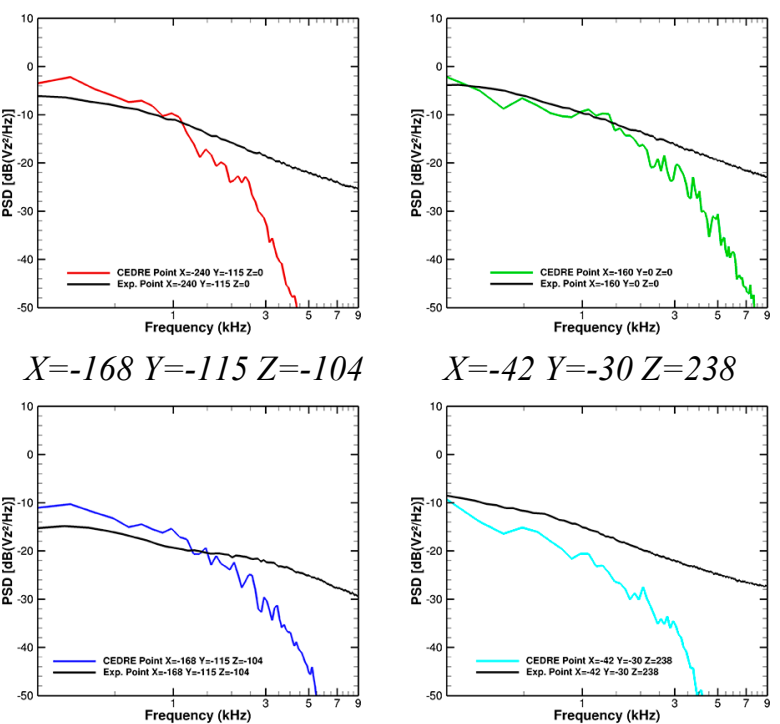

Figure 8. Streamwise (top) and vertical (bottom) velocity spectra at different locations of the wake.

American Institute of Aeronautics and Astronautics 

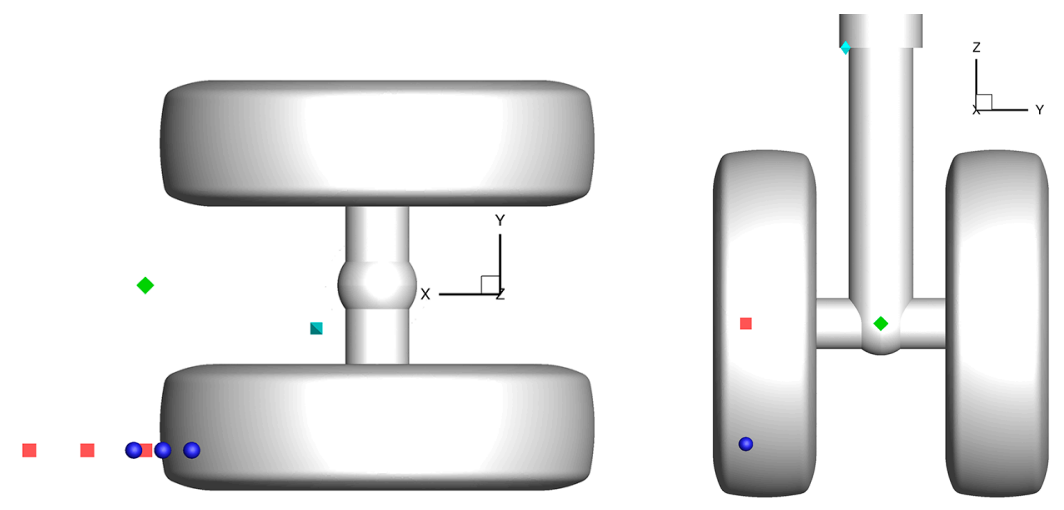

Figure 9. Unsteady two-dimensional LDV chosen locations

\section{B. Wall Pressure Measurements}

\section{Steady Pressure Taps}

Another important parameter to look at is the pressure obtained at the surface of the landing gear. A good prediction is important to ensure the quality of the integral method used for the acoustic post process. We will start with the mean pressure coefficient around the left wheel, which gives us the location of the detachment of the flow. The role that plays the sudden change on the mesh size (see Figure 4) at $\theta=90^{\circ}$ on the location of this point is still to be investigated.

In Figure 11, the comparison against the experimental results shows a remarkable agreement at all the different angular positions. We can conclude that the ZDES model, especially the RANS approach used at the wall works as expected, at least in terms of steady pressure.
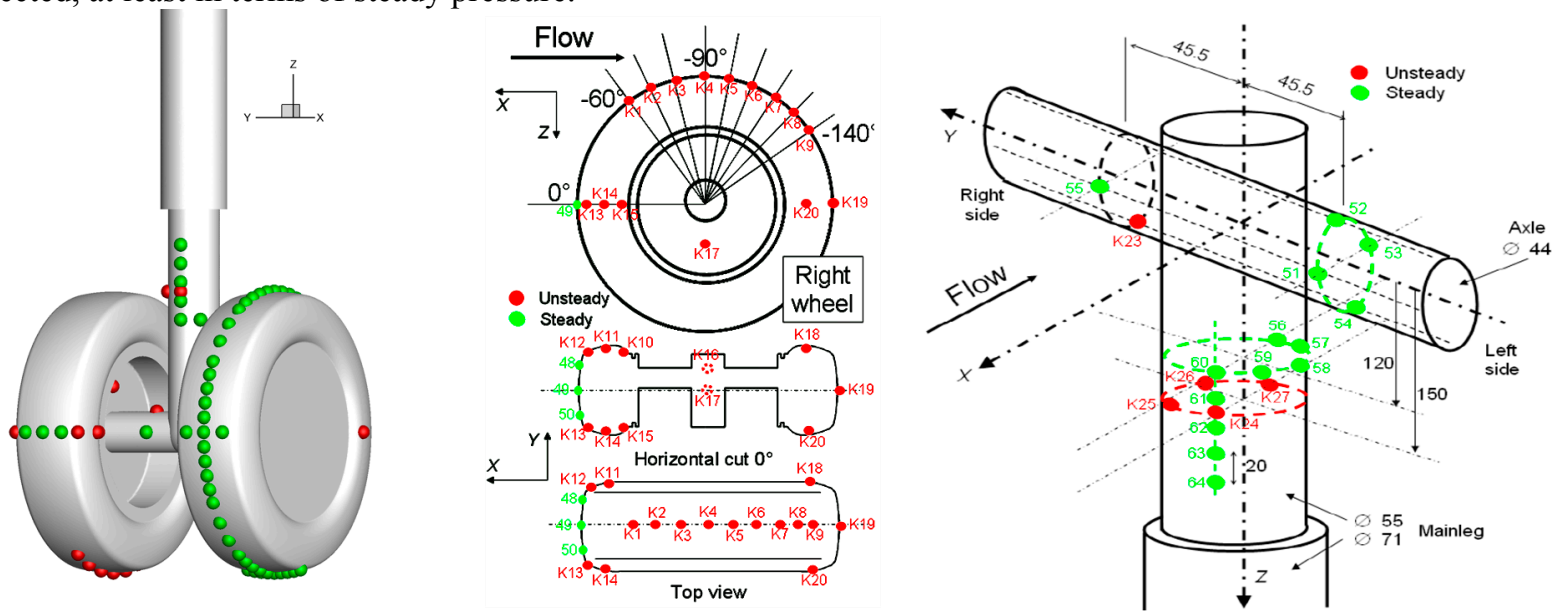

Figure 10. Pressure taps locations. Unsteady taps in red, steady ones in green.

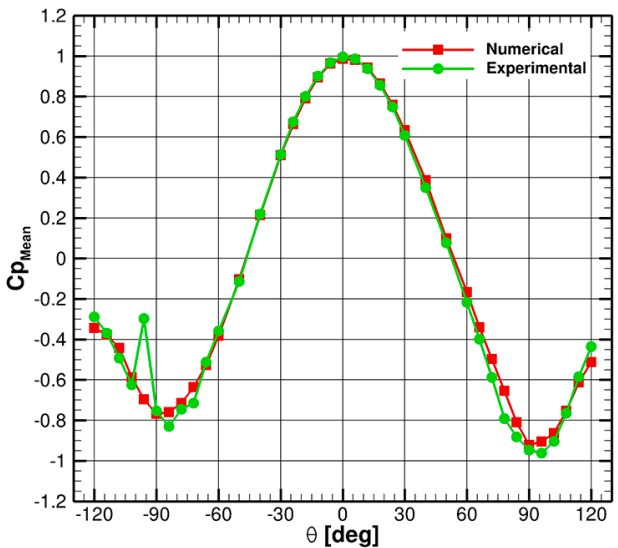

Figure 11. Mean steady pressure coefficient over left wheel. Experiments in green, numerical results in red

American Institute of Aeronautics and Astronautics 


\section{Unsteady Pressure Measurements}

After the study of the mean pressure around the wheel, we proceed to evaluate its spectral content at different locations. All the results shown here have been computed over $100 \mathrm{~ms}$ of signal, averaged over 10 non-overlapping blocks using a Hanning window. In Figure 10 we can observe the location of the different sensors placed on the landing gear. From those sensors, only the result for Kulite numbers 1, 9, 14, 17, 19, 20, 23 and 27 are shown in Figure 12 for the sake of simplicity, covering the main zones of interest over the landing gear.

The first Kulite found in Figure 12 (Kulite 1) is placed just behind the tripping bands (placed at the same angular position as the Kulite 1) used during the F2 campaign. The predicted PSD drops after $2 \mathrm{kHz}$ while the experiments remains constant, the same tendency has been found on other studies, such as Ref. 3 and 6, pointing at the tripping effect even if in these studies the drop is considered to be due to a lack of resolution at the wall. On the other hand, as soon as the flow is detached thanks to the adverse pressure gradient, the ZDES model changes into pure LES and the results better reproduce the experimental ones as observed with Kulites 9 and 19. For the first one, the flow starts to be detached, while for the second one it is completely detached and heavily turbulent. A small overestimation of the level is found, but in general, the numerical results match the experimental ones up to 6 or $7 \mathrm{kHz}$.

Regarding Kulite 14, placed at the upstream inner part of the right wheel, we can observe an overestimation of the lower frequencies, as well as a difference in the width and height of the tonal peaks of the cavity. This mismatch is caused by a too coarse wall resolution, in the streamwise direction, at the location of this Kulite, which affects the formation of the corresponding shear layer, which interacts differently with the cavity. Moreover, the computation frequency resolution could be improved with a longer signal.

Kulite 17 is also shown as it presents the particularity of being placed at the cavity of the wheel. The agreement with the experiments is fairly good, given the complexity of the flow at this location. Simulation shows an overestimation at low frequencies, which might be due to the shortness of the signal.

Kulite 20 is placed at the reattachment point of the flow with the rear part of the wheel. The agreement of this Kulite plus the agreement of Kulite 23 indicates that the flow between the wheels is very well reproduced at this location, despite the multiple interactions with the cavities and the axle.

Finally, Kulite 27, confirms what has been observed with Kulites 20 and 23, this time behind the leg.

It is important to link these spectra with the mean field observed in Figure 6. Despite not having reproduced the tripping used on the experiments, both the mean field and its spectral content are well reproduced even at fairly complex locations.

Kulite 1

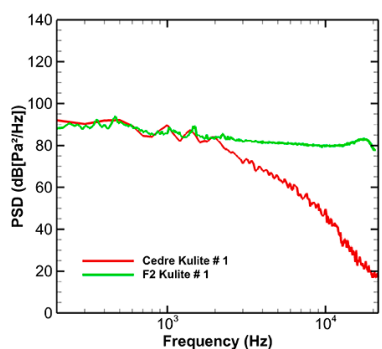

Kulite 19

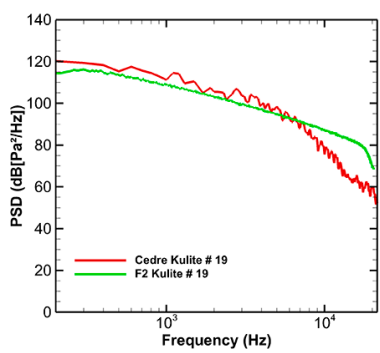

Kulite 9

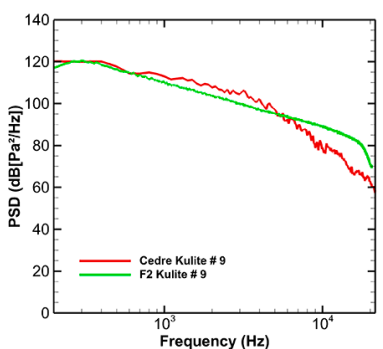

Kulite 20

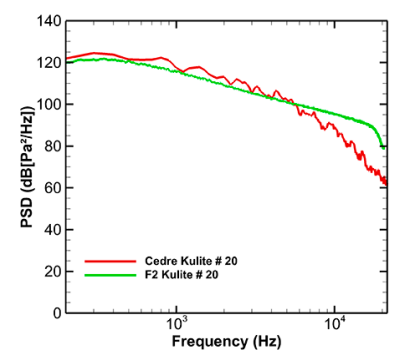

Kulite 14

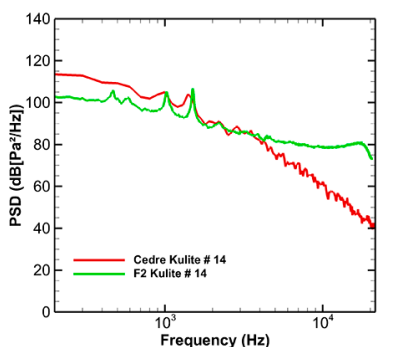

Kulite 23

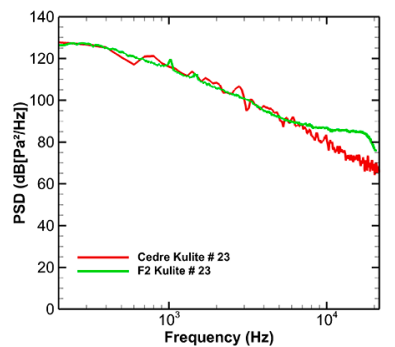

Kulite 17

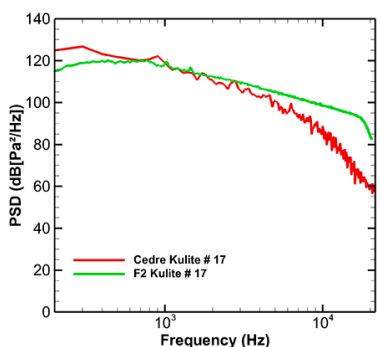

Kulite 27

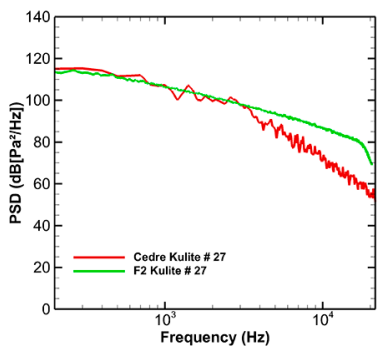

Figure 12. Power spectral density of Kulites. Computational results in red and experiments in green. From left to right and top to bottom, Kulite 1, 9, 14, 17, 19, 20, 23 and 27. 


\section{Aeroacoustic post process}

For the acoustic post process ONERA's in-house code $\mathrm{KIM}^{13,14}$ is used in order to perform the FW-H analogy in the time domain, by using two different acoustic formulations:

- An integration based on the pressure over the solid surface of the landing gear, where only the dipolar sources are considered. The quadripolar terms in the wake are, in this approach, neglected thanks to the low Mach number approach.

- A porous surface integration over the surface shown in Figure 13 (left), where all the sources contained by the surface are considered. As we can also see in Figure 13 (right), the wake is quite long and the vortices shed by the landing gear could cross the porous surface, this effect is referred as cross-wake effect and is known to artificially increase the noise levels. In order to solve this problem, a larger porous surface should be used, placed far enough not to suffer from these perturbations, or a faster coarsening of the mesh should be implemented for dissipating any fluctuation left. These two solutions are opposed to the need of having a sufficiently refined mesh capable of propagating the acoustic waves from the source to the surface, so a compromise is needed.
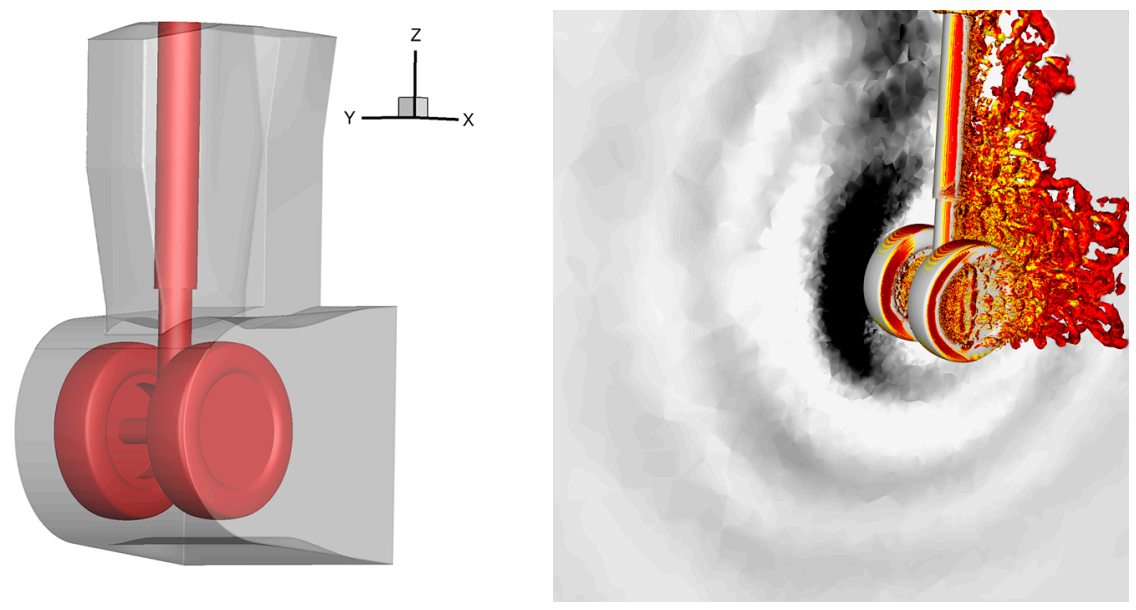

Figure 13. Porous surface around the landing gear for acoustic post-processing (left). Isocontours of $Q$ criterion $\left(10^{6}\right)$ colored by vorticity with dilatation field in grayscale (right)

The aeroacoustic experimental campaign was performed at CEPRA19 where two sets of 12 microphone arcs were placed, one for the flyover measurements and the other one for sideline. As we can observe in Figure 14, the microphones are placed at 6 meters from the landing gear, and spaced $10^{\circ}$ one from the other. The sideline arc was placed at $56^{\circ}$ with respect to the horizontal plane and the microphones distributed as for the flyover.

The experimental results were corrected in order to take into account the atmospheric absorption, the acoustic refraction through the jet shear layer and also the background noise. The presence of the shear layer was taken into consideration on the computation using virtual microphones placed at corrected locations. $102 \mathrm{~ms}$ of signal with 10 non-overlapping blocks and a Hanning window were used for computing the spectra.

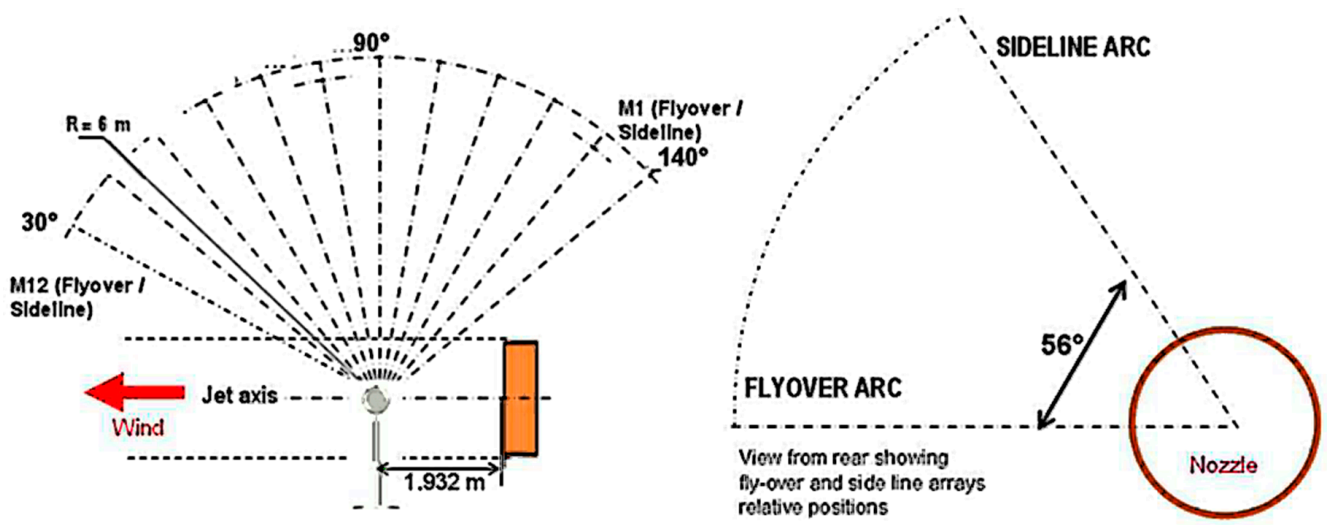

Figure 14. CEPRA 19 Experimental microphone locations

10

American Institute of Aeronautics and Astronautics 


\section{A. Far-field microphones spectra}

\section{FW-H analogy over the model skin}

In Figure 15 the results obtained using the FW-H analogy ${ }^{15}$ over the landing gear skin are presented. We can appreciate a good agreement in flyover, with some overestimations; when going downstream (from right to left) the numerical results tend to overestimate the levels for the lower frequencies.

The same discrepancies are observed at sideline, while overall predicted agreement is lower than in flyover. It is important to notice that for microphone 12, the experimental signal to noise ratio was not good enough at some frequencies, so the real level could not be extracted. In Figure 15 and 16, those frequencies are suppressed in the lowest range, below $500 \mathrm{~Hz}$, and filled between $5 \mathrm{kHz}$ and $10.5 \mathrm{kHz}$ with an straight line for illustration purposes.

Mic. \# 12

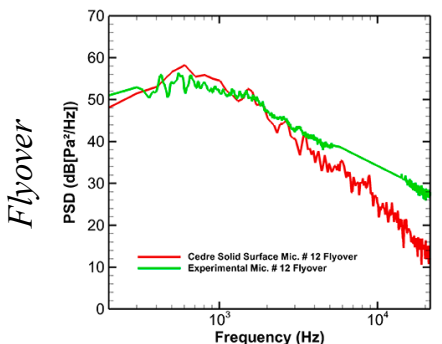

Mic. \# 12

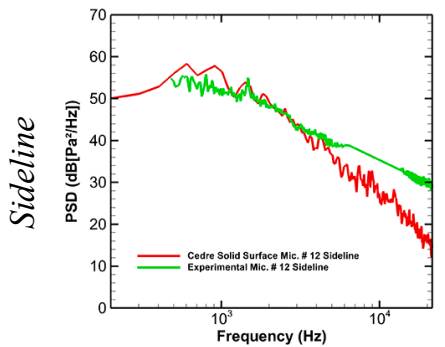

Mic. \# 9

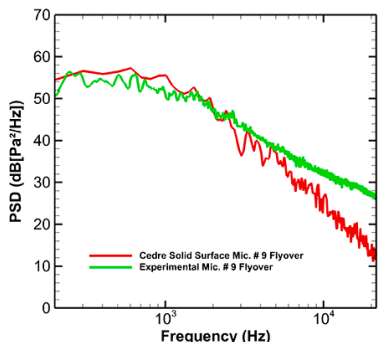

Mic. \# 9

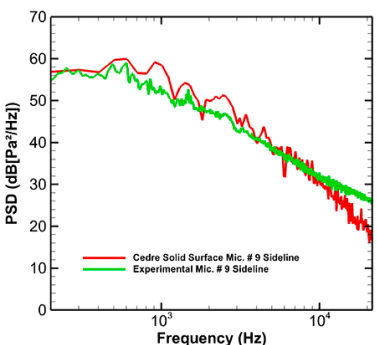

Mic. \# 6

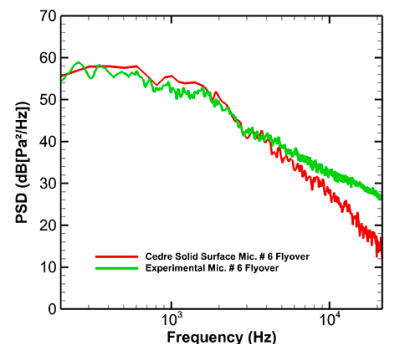

Mic. \# 6

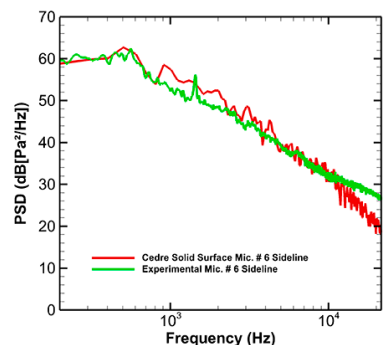

Mic. \# 3

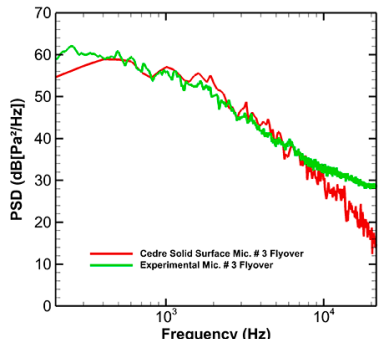

Mic. \# 3

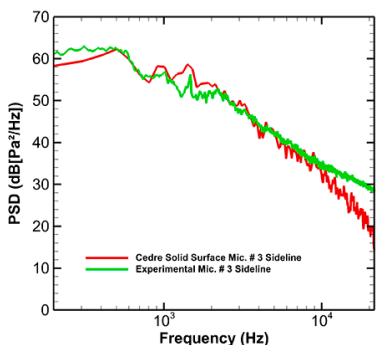

Figure 15. Far field acoustics PSD in Flyover (top) and Sideline (bottom) for microphones 3, 6, 9 and 12 using the solid surface approach. CEDRE results in red, CEPRA 19 experimental results in green.

Mic. \# 12

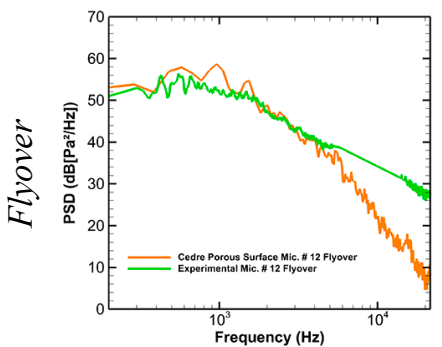

Mic. \# 12

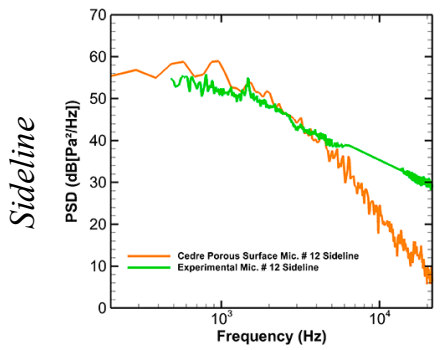

Mic. \# 9

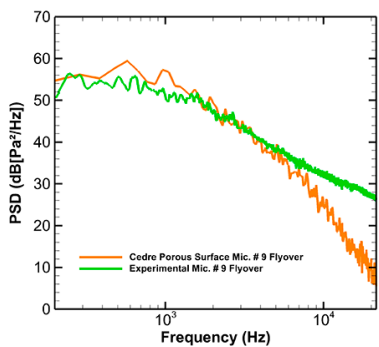

Mic. \# 9

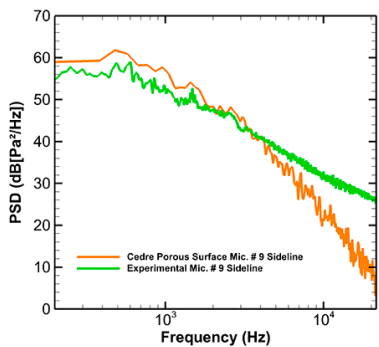

Mic. \# 6

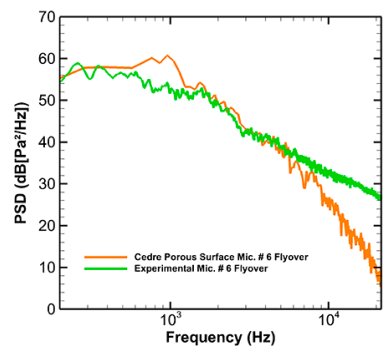

Mic. \# 6

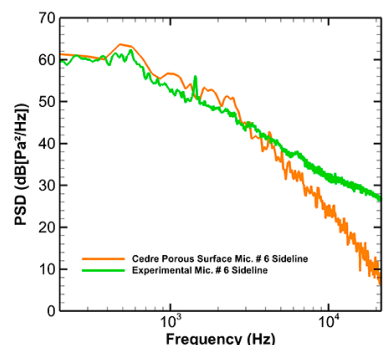

Mic. \# 3

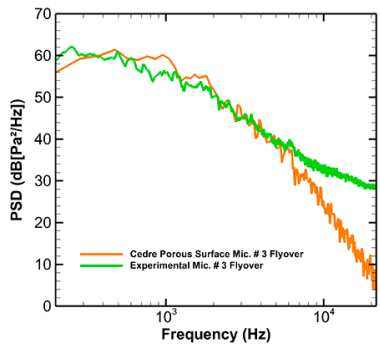

Mic. \# 3

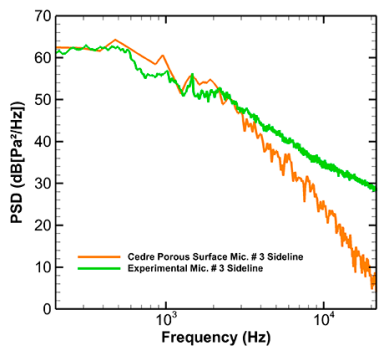

Figure 16. Far field acoustics PSD in Flyover (top) and Sideline (bottom) for microphones 3, 6, 9 and 12 using the porous surface approach. CEDRE results in orange, CEPRA 19 experimental results in green. 


\section{FW-H analogy over the porous surface}

As for the solid surface, the results obtained over the porous surface (see Figure 13) are shown in Figure 16.

Due to the need of accurately propagating the acoustic waves from the source to the porous surface, and considering that the mesh becomes coarser quite close to the wall, the porous surface used was placed quite close to the landing gear as discussed at the beginning of this section. This has a twofold effect, on one hand, due to the proximity of the surface to the landing gear, the cut-off frequency is preserved with respect to the solid surface. On the other hand, there is an overestimation of the levels that could be due to the cross-wake effect. Once again, the results are found to be in a good agreement with the experimental ones, but we can conclude that the use of this porous surface did not improve the acoustic prediction compared to the solid surface one.

\section{B. Far-Field Microphones Overall Sound Pressure Level}

1. Solid vs. Porous surface integration

The spectra shown in the previous paragraph were integrated between $200 \mathrm{~Hz}$ and $5 \mathrm{kHz}$ (frequencies beyond do not play any role because of their decreasing amplitudes). The lowest frequency range in the computation is still to be improved with a finer frequency resolution, which means a longer signal. This lower range is responsible of the biggest part of the overestimation shown in Figure 17, hence, it is believed by the authors that a longer signal would greatly improve the integral levels.

In flyover, there is an overestimation of the levels by $3 \mathrm{~dB}$ for the porous surface and only by $1.5 \mathrm{~dB}$ for the solid surface downstream the landing gear. Results are better in the upstream arc, presenting an error of less than $0.5 \mathrm{~dB}$ for the solid surface and about $1 \mathrm{~dB}$ for the porous surface.

In sideline, the tendency is the same as in flyover. In this case, downstream the errors are about 4 and $2 \mathrm{~dB}$ for the porous and solid surface integration, respectively. Upstream the prediction tends to agree with the experimental result for the solid surface, while for the porous still produces an error of $2 \mathrm{~dB}$.
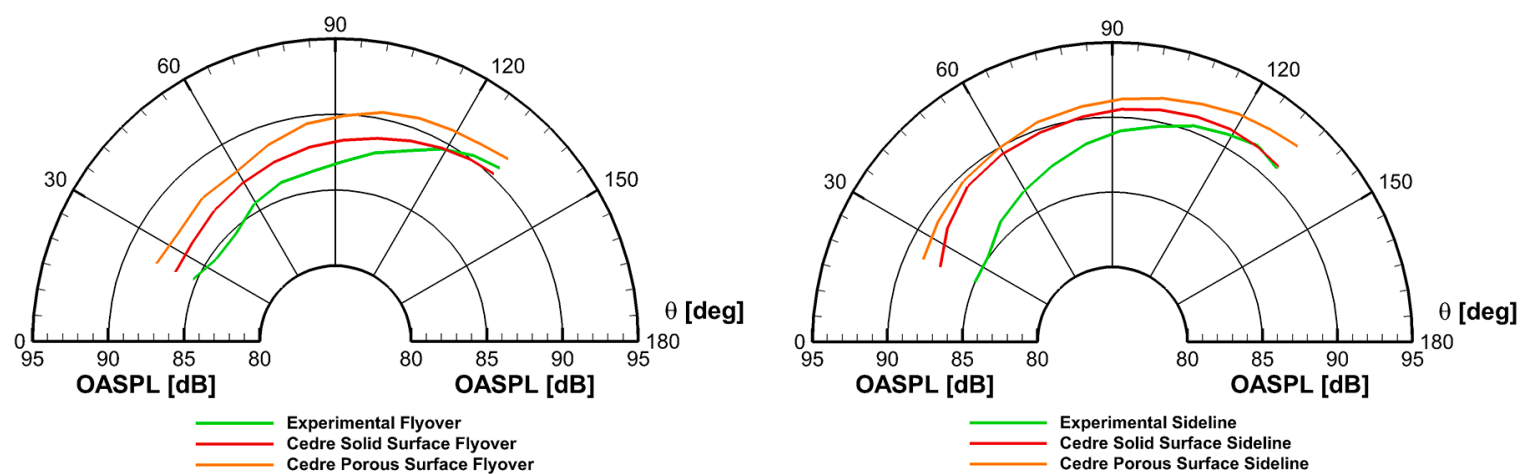

Figure 17. Overall sound pressure level integrated from $200 \mathrm{~Hz}$ to $5 \mathrm{kHz}$. Flyover results (left) and Sideline (right). Experimental results in green, solid surface analogy in red and porous surface results in orange.

\section{Noise directivity and geometrical elements influence on the OASPL}

Finally, in order to have an idea of the influence the different geometrical parts have on the directivity patterns, a set of three circular virtual microphone antennas with microphones at every degree was placed at six meters from the landing gear. The chosen planes to contain them were $\mathrm{X}=0, \mathrm{Y}=0$ and $\mathrm{Z}=0$.

We performed the FW-H analogy over selected parts of the solid surface of the landing gear. Figure 18 presents these parts with the same color scheme as the one used in Figure 19.

In Figure 19, we can see in light blue the OASPL just considering both wheels of the landing gear without their internal cavities. These cavities are added afterwards and the results are plotted in green. The influence of the axle was also addressed by adding this element to the previous ones, producing the dark blue line. Finally, the whole landing gear is considered by adding the leg, results are shown in red. 


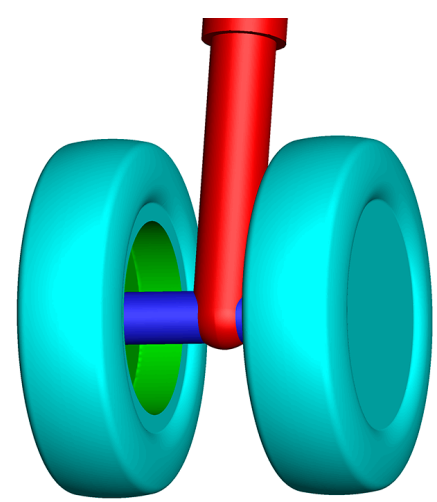

Figure 18. LAGOON Landing gear decomposed into its main elements
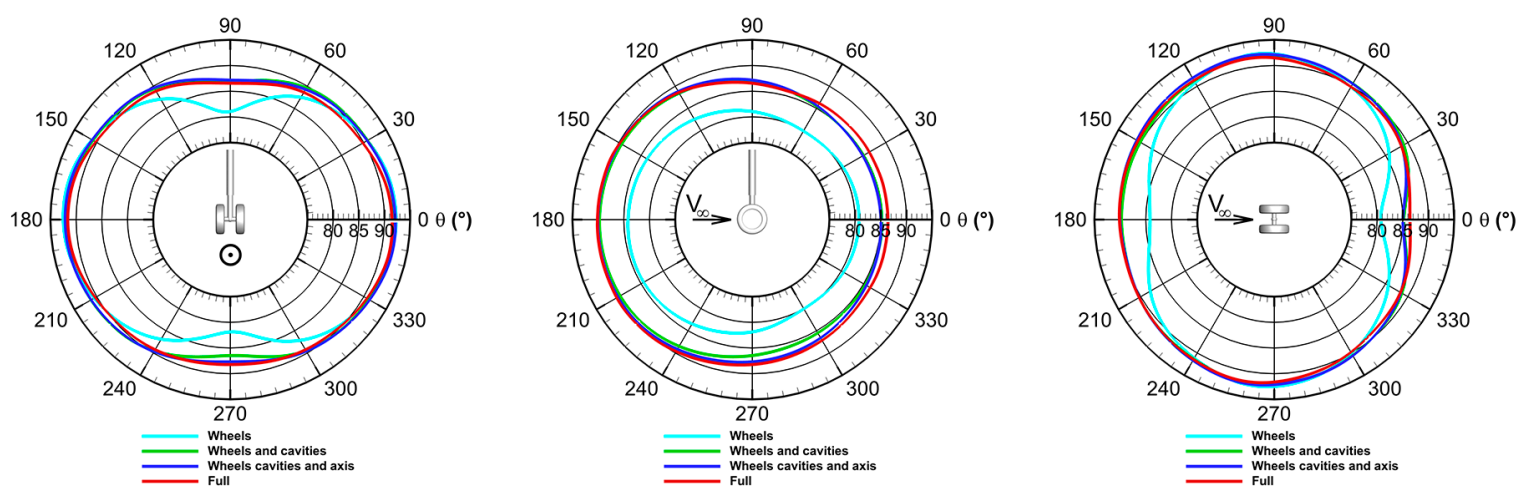

Figure 19. Influence of the different geometrical parts on the overall sound pressure level integrated from 200 Hz to $5 \mathrm{kHz}$ over a sphere of $6 \mathrm{~m}$ in radius. $X=0$ (left), $Y=0$ (middle) and $Z=0$ (right).

The most contributing elements, apart from the wheels, are the cavities, which not only are responsible for the tonal peaks observed in the spectra, but also contribute to the total noise by adding $5 \mathrm{~dB}$ to the noise coming from the wheels in the streamwise direction, and also in flyover. In sideline, these elements do not play a significant role except when approaching to 0 or 180 degrees.

The axle and the main leg, despite being located inside the heavily turbulent flow between the wheels seem to have a weak contribution to the total noise.

\section{General conclusions}

Despite a relatively low computational cost, the numerical activity presented in this paper provides accurate aerodynamic and acoustic results of the LAGOON simplified landing gear, using unstructured meshes and the CEDRE code.

The general approach and methodology that have been used can still be improved in several directions. The first point to focus on would be to improve the grid resolution at locations where adverse pressure gradients are found, such as the upstream inner part of the wheel. Another important point is how the effect of the tripping used on the experiments can be reproduced, which has an obvious impact on the fluctuating pressure at the wall, and could also explain some of the weak points found in this simulation.

The last aspect to improve is the election of the porous surface used for the FW-H analogy, election that is still quite arbitrary. At this end, a surface extending over a larger streamwise distance would certainly provide better results, avoiding the wake to cross it. Furthermore, other less dissipative numerical schemes can be used, that could help mitigating this problem. As they are more expensive, a compromise should be found with the mesh size that could be in that case coarser. 


\section{Acknowledgements}

The authors would like to thank Eric Manoha from ONERA for its continuous help and support on the development of this study as well as for sharing with us his knowledge on this configuration.

Finally, they also acknowledge the fruitful exchanges with Philippe Druault from UPMC-Paris VI University.

\section{References}

${ }^{1}$ Manoha, E., Bulté, J., and Caruelle, B., "Lagoon: An Experimental Database for the Validation of CFD/CAA Methods for Landing Gear Noise Prediction," American Institute of Aeronautics and Astronautics, 2008.

2 Manoha, E., Bulte, J., Ciobaca, V., and Caruelle, B., "LAGOON: Further Analysis of Aerodynamic Experiments and Early Aeroacoustics Results," American Institute of Aeronautics and Astronautics, 2009.

${ }^{3}$ Sanders, L., Manoha, E., Ben Khelil, S., and Francois, C., "LAGOON : CFD/CAA Coupling for Landing Gear Noise and Comparison with Experimental Database," American Institute of Aeronautics and Astronautics, 2011.

${ }^{4}$ Sanders, L., Manoha, E., Ben Khelil, S., and Francois, C., "LAGOON: New Mach Landing Gear Noise Computation and further analysis of the CAA process," American Institute of Aeronautics and Astronautics, 2012.

${ }^{5}$ Sanders, L., Manoha, E., Ben Khelil, S., and François, C., "CFD/CAA coupling on the LAGOON \#2 landing gear using a structured multi-block solver with the Chimera technique," American Institute of Aeronautics and Astronautics, 2013.

${ }^{6}$ Giret, J.-C., Sengissen, A., Moreau, S., and Jouhaud, J.-C., "Prediction of LAGOON landing-gear noise using an unstructured LES Solver," American Institute of Aeronautics and Astronautics, 2013.

${ }^{7}$ Ribeiro, A. F., Casalino, D., Fares, E., and Noelting, S. E., "CFD/CAA Analysis of the LAGOON Landing Gear Configuration," American Institute of Aeronautics and Astronautics, 2013.

${ }^{8}$ Liu, W., Wook Kim, J., Zhang, X., Angland, D., and Caruelle, B., "Landing-gear noise prediction using high-order finite difference schemes," Journal of Sound and Vibration, vol. 332, Jul. 2013, pp. 3517-3534.

${ }^{9}$ Spalart, P., Jou, W., Strelets, M., and Allmaras, S., "Comments of feasibility of LES for wings, and on a hybrid RANS/LES approach," 1997.

${ }^{10}$ Spalart, P. R., Deck, S., Shur, M. L., Squires, K. D., Strelets, M. K., and Travin, A., "A New Version of Detachededdy Simulation, Resistant to Ambiguous Grid Densities," Theoretical and Computational Fluid Dynamics, vol. 20, Jul. 2006, pp. 181-195.

${ }^{11}$ Deck, S., "Recent improvements in the Zonal Detached Eddy Simulation (ZDES) formulation," Theoretical and Computational Fluid Dynamics, vol. 26, Dec. 2012, pp. 523-550.

${ }^{12}$ F. Houssen, F. Vuillot, E. Manoha, and S. Redonnet, "Aeroacoustic simulations of supercritical tandem cylinder," Stockholm, Sweden: American Institute of Aeronautics and Astronautics, 2010.

${ }^{13}$ Prieur, J., and Rahier, G., "Aeroacoustic integral methods, formulation and efficient numerical implementation," Aerospace Science and Technology, vol. 5, Oct. 2001, pp. 457-468.

${ }^{14}$ Rahier, G., Prieur, J., Vuillot, F., Lupoglazoff, N., and Biancherin, A., "Investigation of integral surface formulations for acoustic post-processing of unsteady aerodynamic jet simulations," Aerospace Science and Technology, vol. 8, Sep. 2004, pp. 453-467.

${ }^{15}$ Williams, J. E. F., and Hawkings, D. L., "Sound Generation by Turbulence and Surfaces in Arbitrary Motion," Philosophical Transactions of the Royal Society of London. Series A, Mathematical and Physical Sciences, vol. 264, May 1969, pp. 321-342. 



\section{ONERA}

BP 72 - 29 avenue de la Division Leclerc - 92322 CHATILLON CEDEX - Tél. : +33 146734040 - Fax : +33 146734141

w w w. onera.f r 